\title{
Designing Physics Hands-On Experiment for Distance Learning Using Arduino and Block-Based Programing Language
}

\author{
Elisabeth Pratidhina ${ }^{1}$, Dadan Rosana ${ }^{2}$, Heru Kuswanto ${ }^{3}$ \\ ${ }^{1}$ Universitas Negeri Yogyakarta, Jalan Colombo Sleman, Yogyakarta, Indonesia; Physics Department, \\ Widya Mandala Surabaya Catholic University, Surabaya, Indonesia \\ ${ }^{2}$ Department of Science Education, Universitas Negeri Yogyakarta, Jalan Colombo Sleman, \\ Yogyakarta, Indonesia \\ ${ }^{3}$ Department of Physics Education, Universitas Negeri Yogyakarta, Jalan Colombo Sleman, \\ Yogyakarta, Indonesia
}

\begin{abstract}
Experiment activity is an essential part of physics learning because it engages students to interact with real physics phenomena and develop their scientific abilities. However, online physics learning still faces a challenge in providing experiment access to the student. In this paper, we propose an alternative experiment activity to explore Ohm's Law in physics class. The experiment incorporates Arduino and a block-based programming language called CommonCoding Builder (CCB). Arduino Uno is an affordable microcontroller that can be used to measure many physics quantities. Programming using CCB can be carried out by students who have never learned to program before. Hence, the combination of Arduino Uno and CCB offers engaging and affordable experiment activities in online learning.
\end{abstract}

Keywords - online learning, physics experiment, Ohm's law, Arduino, block-based programming.

DOI: 10.18421/TEM111-47

https://doi.org/10.18421/TEM111-47

Corresponding author: Elisabeth Pratidhina,

Postgraduate Program, Universitas Negeri Yogyakarta \& Physics Department, Widya Mandala Surabaya Catholic University, Surabaya, Indonesia.

Email: elisa.founda@gmail.com

Received: 27 November 2021.

Revised: 10 February 2022.

Accepted: 15 February 2022.

Published: 28 February 2022.

(cc) BY-NC-ND (C) 2022 Elisabeth Pratidhina, Dadan Rosana \& Heru Kuswanto; published by UIKTEN. This work is licensed under the Creative Commons AttributionNonCommercial-NoDerivs 4.0 License.

The article is published with Open Access at https://www.temjournal.com/

\section{Introduction}

Distance learning has grown significantly due to the tremendous development of communication technology. The past main obstacle of distance

learning was the lack of interactions among students and teachers. Nowadays, those interactions can be facilitated through various online platforms such as zoom and Google Meet [1], [2]. However, in science class, distance learning still faces some challenges, especially related to experimental activities.

Experimental work plays an important role in physics learning. Through experiments, students can develop their scientific abilities [3], improve their attitude toward science [4], and understand the nature of science, and the process of scientific investigation [5]. In online learning, the challenge is to facilitate students in doing experimental work safely and effectively. Some alternative activities, such as demonstration through video and computer simulation, have their limit [6], [7]. They cannot bring authentic experiment experience that allows students to practice handling instruments safely, do the real measurement, be aware of the uncertainty in measurement, and model natural phenomena.

Students may perform physics experiments at home by using an experiment kit. There are some kits in the market, but the price may not be affordable. As an alternative, teachers can design a cheap experimental kit using Arduino Uno. Arduino Uno is a low-cost microcontroller that can be used as measurement tools and direct current source for many practical projects, such as determining diode characteristics [8], investigating resistor-capacitor circuit properties [9], determining Planck constant [10], measuring electrical power of solar cell [11], and so on. Using Arduino also can create interest in physics [12]. 
Arduino Uno usually can work within $\mathrm{C}$ or $\mathrm{C}++$ programming, which may be difficult for students who have not learned the programing language before [13]. Fortunately, simple Arduino Uno programming can be done using block-based programming, such as Common-Coding Builder (CCB). In CCB, all syntax is presented as blocks. Users can construct programs by combining some blocks, just like play puzzles. Hence, physics experiments with Arduino Uno and CCB can also introduce programming to students.

In this paper, we discuss Arduino Uno and CCB as a didactic tool for online physics learning. We give an example of how to use those didactic tools to explore the concepts of Ohm's Law.

\section{Theory of Ohm's Law}

Consider a conductor wire with a length of $l$ and a cross-sectional area of $A$ (see Figure 1). Across the wire, a potential difference of $\Delta V$ is applied.

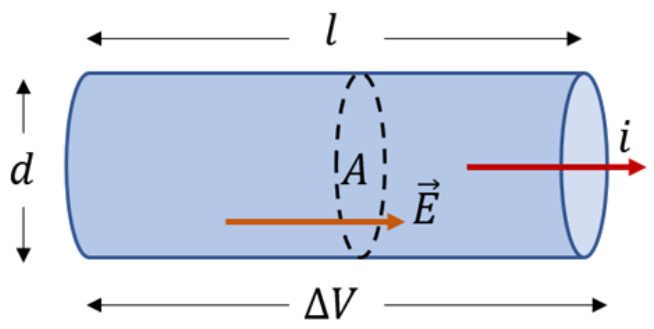

Figure 1. A conductor with a length of $l$, a cross-sectional area of $A$, a diameter of $d$ and a potential difference of $\Delta V$.

When a potential difference is applied across a conductor, a current density $(J)$ and an electric field $(E)$ are established. In some materials, including conductor, the current density is proportional to the electric field [14],

$$
\vec{J}=\sigma \vec{E},
$$

where $\vec{J}, \vec{E}$, and $\sigma$ represent current density, electric field, and conductivity, respectively. Equation (1) is called Ohm's law. Material that follows equation (1) is called ohmic material.

Due to the potential difference, an electric field will be established. The magnitude of the electric field, $E$, will follow:

$$
\Delta V=E l
$$

By substituting equation (1) to (2), we will get,

$$
J=\sigma E=\frac{\sigma \Delta V}{l}
$$

Because $J=i / A$, the potential difference across the conducting wire becomes:

$$
\Delta V=\frac{l}{\sigma} J=\left(\frac{l}{\sigma A}\right) i=R i,
$$

$\frac{l}{\sigma A}$ is defined as resistance $(R)$. Hence the resistance of a conducting wire can be determined through:

$$
R=\frac{1}{\sigma} \frac{l}{A}
$$

$1 / \sigma$ is also called resistivity $(\rho)$. Thus,

$$
R=\rho \frac{l}{A}
$$

From equation (6) above, we can conclude that theoretically, the resistance of the conductor wire is linearly proportional to conductor length, $l$ and inversely proportional to the cross-sectional area of the conductor, $A$. The relationship in equation (6) will be explored experimentally by using Arduino Uno and CCB.

\section{Experimental Set-up}

\subsection{Hardware Setup}

The goal of the experiment is to explore equation (6) through the experiment. For investigations, we need some components such as Arduino Uno, breadboard, jumper wires, resistor $(100 \mathrm{ohm})$, ruler, and pencil leads with various diameters from the same brand and type. Typically, pencil lead is made from graphite, and graphite is known as conductor material. We measure the resistance of pencil lead with various cross-sectional areas and lengths by using Arduino Uno and CCB. The circuit design to measure resistance can be seen in Figure 2. The experiment setup is shown in Figure 3.

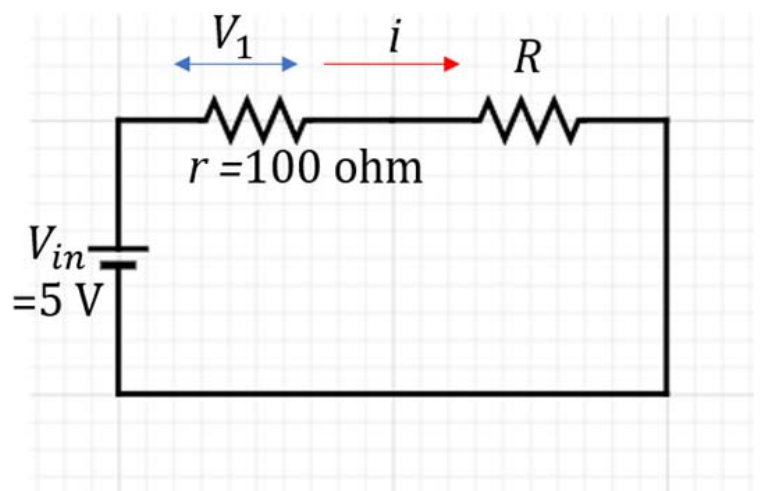

Figure 2. Circuit diagram to measure the resistance of a component, $R$

According to Kirchoff rule,

$$
\begin{aligned}
& V_{\text {in }}=i(r+R) \\
R= & \frac{V_{\text {in }}}{i}-r
\end{aligned}
$$


Since $i=\frac{V_{1}}{r}$, equation $(7)$ can be modified to:

$$
R=V_{\text {in }} \frac{r}{V_{1}}-r=r\left(\frac{V_{\text {in }}}{V_{1}}-1\right)
$$

Where $R$ is the resistance of pencil lead that we want to measure, $r$ is the resistance of a resistor in the circuit (we use a 100 -ohm resistor), $V_{i n}$ is the input voltage $\left(V_{\text {in }}=5 \mathrm{~V}\right)$, and $V_{1}$ is the potential difference across $r$. $V_{1}$ can be yielded from the reading value of analog pin $A 4$ and $A 5$.

$$
V_{1}=(A 4-A 5) * 5 / 1023
$$

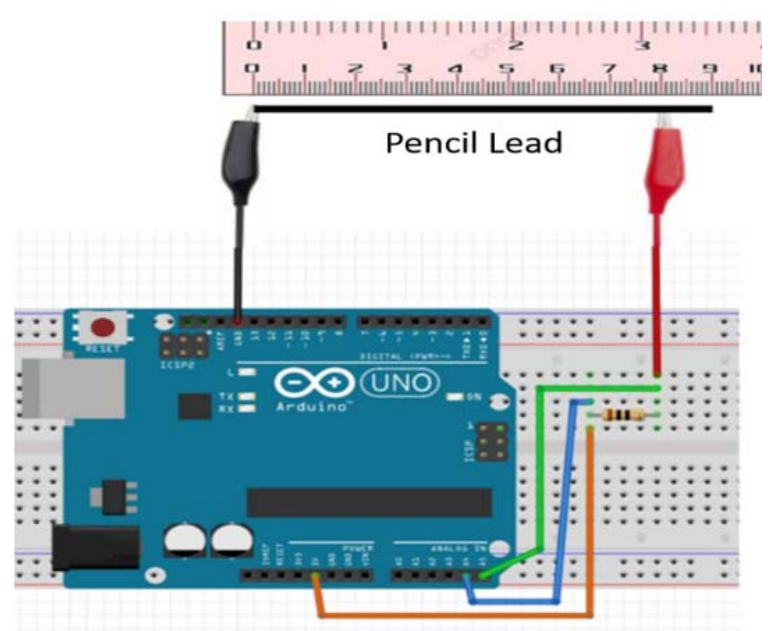

Figure 3. Setup experiment to measure pencil lead resistance with the variation of length

\subsection{Programming}

The Arduino Uno can be programmed using CCB that can be accessed at https://common-coding.com/. The interface of CCB is shown in Figure 4. Arduino programming can be carried out with an extension feature that can be added by choosing menu $E x>$ Arduino for Windows. CCB can read the Arduino Uno board connected through a USB port after running a firmware software called ccb_connect.exe that can be downloaded from the common-coding website. The firmware software can be run in a Java environment.

After the connection between Arduino and CCB has been set up, the user can construct a block script in Figure 5 to order Arduino Uno to measure $R$.
Code Tab

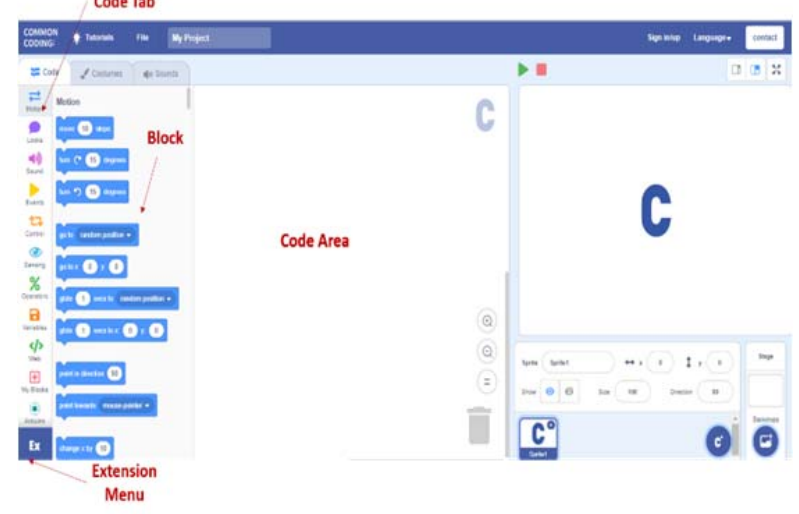

Figure 4. Interface of $C C B$

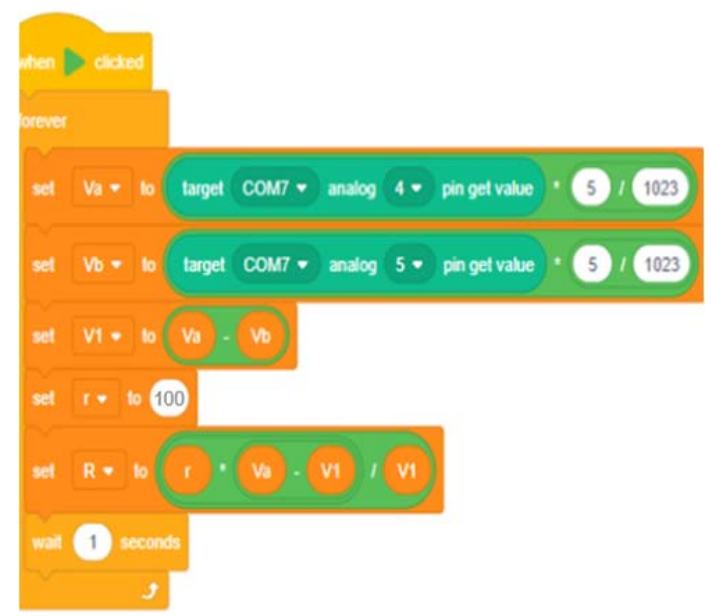

Figure 5. Block-script to measure resistance $R$

\section{Results and Discussions}

Table 1 shows the data yield from the experiment with various pencil lead diameters, $d$. The crosssectional area of the pencil lead can be calculated from $A=\pi\left(\frac{d}{2}\right)^{2}$. The relation between $A$ and $R$ is depicted in Figure 6(a). It can be seen that $R$ are inversely proportional to $A$. Moreover, from Figure 6(b), we also conclude that $R$ is linearly proportional to $1 / A$.

Table 1. Experimental Data (Variation of cross-sectional area)

\begin{tabular}{|c|l|c|c|c|}
\hline$l(\mathrm{~m})$ & $\mathrm{d}(\mathrm{m})$ & $A\left(\mathrm{~m}^{2}\right)$ & $1 / A\left(\mathrm{~m}^{-2}\right)$ & $R(\mathrm{ohm})$ \\
\hline 0.09 & 0.0005 & $1.96 \times 10^{-7}$ & 5092958 & 3.8 \\
\hline 0.09 & 0.0007 & $3.85 \times 10^{-7}$ & 2598448 & 3.2 \\
\hline 0.09 & 0.0009 & $6.36 \times 10^{-7}$ & 1571901 & 2.7 \\
\hline
\end{tabular}


(a)
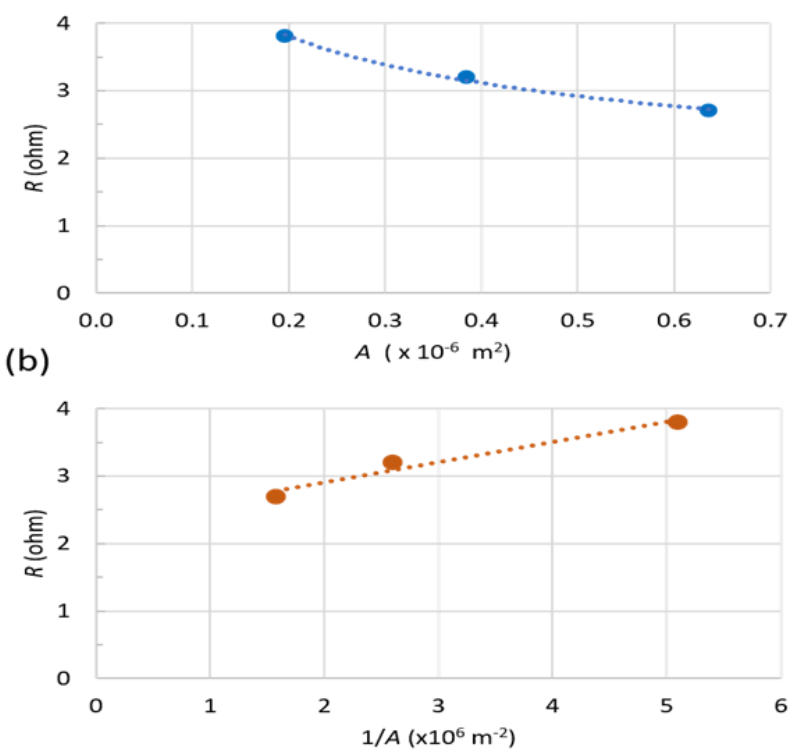

Figure 6. Relationship between resistance, $R$ with (a) cross-sectional area, $A$ and (b) inverse cross-sectional area, $1 / A$.

Table 2 shows the data yield from the experiment with various pencil lead lengths, $l$. In this experiment, pencil lead with a diameter of $2 \mathrm{~mm}$ is used. Figure 7 shows the relation between $R$ and $l$. It can be seen that $R$ is directly proportional to $l$.

Table 2. Experimental Data (Variation of length)

\begin{tabular}{|c|c|c|}
\hline$d(\mathrm{~m})$ & $l(\mathrm{~m})$ & $R(\mathrm{ohm})$ \\
\hline 0.002 & 0.03 & 5.7 \\
\hline 0.002 & 0.04 & 6.4 \\
\hline 0.002 & 0.05 & 7.1 \\
\hline 0.002 & 0.06 & 8.1 \\
\hline 0.002 & 0.07 & 8.6 \\
\hline 0.002 & 0.08 & 9.3 \\
\hline
\end{tabular}

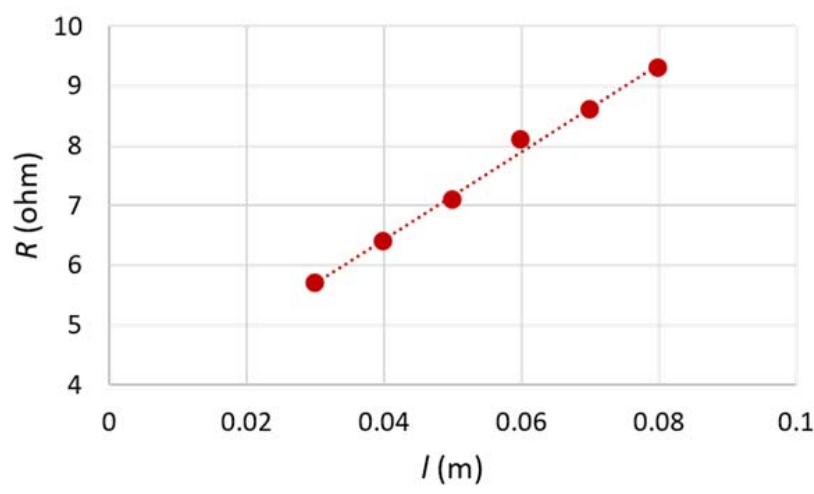

Figure 7. Relationship between resistance, $R$ and length, $l$

\section{Conclusions}

Arduino and $\mathrm{CCB}$ can become affordable experiment kits to explore various physics phenomena. In this paper, we have explained the use of Arduino and CCB to prove Ohm's law experimentally. The designed experiment demonstrates that the conductor's resistance is proportional to the length and inversely proportional to the cross-sectional area. The integration of Arduino and CCB in physics experiments may also develop students' computational thinking and coding skills.

\section{Acknowledgments}

This work is a part of project entitled "Development of Modeling Instruction in Online Physics Course to Improve Students' Computational Thinking Skills", which is conducted from 2021-2022. The project is supported financially by Indonesian Ministry of Education, Culture, Research, and Technology through Doctoral Dissertation Grant with contract number: 134/E4.1/AK.04.PT/2021 and T/10.21/UN34.21/PT.01.03/2021.

\section{References}

[1]. Lenkaitis, C. A. (2020). Technology as a mediating tool: videoconferencing, L2 learning, and learner autonomy. Computer Assisted Language Learning, 33(5-6), 483-509. https://doi.org/10.1080/09588221.2019.1572018

[2]. Camargo, C. P., Tempski, P. Z., Busnardo, F. F., Martins, M. D. A., \& Gemperli, R. (2020). Online learning and COVID-19: a meta-synthesis analysis. Clinics, 75.

https://doi.org/10.6061/clinics/2020/e2286

[3]. Etkina, E., Karelina, A., Ruibal-Villasenor, M., Rosengrant, D., Jordan, R., \& Hmelo-Silver, C. E. (2010). Design and reflection help students develop scientific abilities: Learning in introductory physics laboratories. The Journal of the Learning Sciences, 19(1), 54-98. https://doi.org/10.1080/10508400903452876

[4]. Musasia, A. M., Abacha, O. A., \& Biyoyo, M. E. (2012). Effect of Practical Work in Physics on Girls' Performance, Attitude change and Skills acquisition in the form two-form three Secondary Schools' transition in Kenya. International Journal of Humanities and Social Science, 2(23), 151-166.

[5]. Moeed, A. (2013). Science investigation that best supports student learning: Teachers' understanding of science investigation. International Journal of Environmental and Science Education, 8(4), 537-559. https://doi.org/10.12973/ijese.2013.218a

[6]. Aththibby, A. R., Kuswanto, H., \& Mundilarto. (2021). Experiments in Physics Learning in the COVID-19 Era: Systematic Literature Review. Advances in Social Science, Education, and Humanities Research, 528, 458-464. https://doi.org/10.2991/assehr.k.210305.067 
[7]. Leblond, L., \& Hicks, M. (2021). Designing laboratories for online instruction using the iOLab device. The Physics Teacher, 59(5), 351-355. https://doi.org/10.1119/10.0004886

[8]. Önder, F., Önder, E. B., \& Oğur, M. (2019). Determination of diode characteristics by using Arduino. The Physics Teacher, 57(4), 244-245. https://doi.org/10.1119/1.5095382

[9]. Galeriu, C., Letson, C., \& Esper, G. (2015). An Arduino investigation of the $\mathrm{RC}$ circuit. The Physics Teacher, 53(5), 285-288. https://doi.org/10.1119/1.4917435

[10]. de Oliveira, I. N., Ramos, J. A., Silva, W. L., Chaves, V. D., \& de Melo, C. A. (2020). Estudo das propriedades do Diodo Emissor de Luz (LED) para a determinação da constante de Planck numa maquete automatizada com o auxílio da plataforma Arduíno. Revista Brasileira de Ensino de Física, 42, e20190105.

https://doi.org/10.1590/1806-9126-rbef-2019-0105
[11]. Pusch, A., Ubben, M. S., Laumann, D., Heinicke, S., \& Heusler, S. (2021). Real-time data acquisition using Arduino and phyphox: measuring the electrical power of solar panels in contexts of exposure to light in physics classroom. Physics Education, 56(4), 045001. https://doi.org/10.1088/1361-6552/abe993

[12]. Chaudry, A. M. (2020). Using Arduino Uno microcontroller to create interest in physics. The Physics Teacher, 58(6), 418-421. https://doi.org/10.1119/10.0001841

[13]. da Silva, L. F., \& Carvalho, P. S. (2020). Using scratch programming to control photogates in educational physics experiments. Physics Education, 55(1), 013001. https://doi.org/10.1088/1361-6552/ab49e0

[14]. Serway, R. A., \& Jewett, J. W. (2015). Physics for scientists and engineers with modern physics, technology update. Cengage Learning. 